\title{
HILGARDIA
}

A Journal of Agricultural Science Published by the California Agricultural Experiment Station

\section{EXPERIMENTAL STUDIES ON PREDATION: \\ Predation and Cyclamen-Mite Populations \\ on Strawberries in California}

C. B. HUFFAKER and C. E. KENNETT

UNIVERSITY OF CALIFORNIA • BERKELEY, CALIFORNIA 
A native predatory mite, Typhlodromus sp., normally gives good control of the cyclamen mite, Tarsonemus pallidus Banks, in older plantings of strawberries in California. But because of delay in entrance of the predator, control is only sporadic in second-year plantings.

In field trials, stocking of strawberry plantings with the predator late in the first or early in the second year, gave consistent control. The commercial feasibility of the method is still under investigation.

The results have significance in relation to theories of population dynamics, a field in which there have been few controlled experiments. Some recent work on vertebrate predation has been interpreted as more generally applicable to all predation than is justified. Conclusions minimizing the role of such predation in the regulation of prey populations is not transferrable to the field of biological control of insects, for example.

Typhlodromus sp. is a specific predator of cyclamen mite, and its biology is closely correlated with that of its prey, on which its reproduction depends. It can, however, utilize honeydew and other liquid foods for survival during very low densities of the prey. At such low densities the strawberry plant provides maximum protection for the cyclamen mite; and this, together with spatial factors, insure that the pest will not be entirely eliminated by its predator. Under such circumstances, effective predation is not, as some ecologists have postulated, self-annihilative. Rather, the data indicate fairly regular, reciprocally dependent oscillations of predator and pest (prey) populations, with the pest held to economically unimportant levels. Predation may be superimposed over all other mortality causes. 


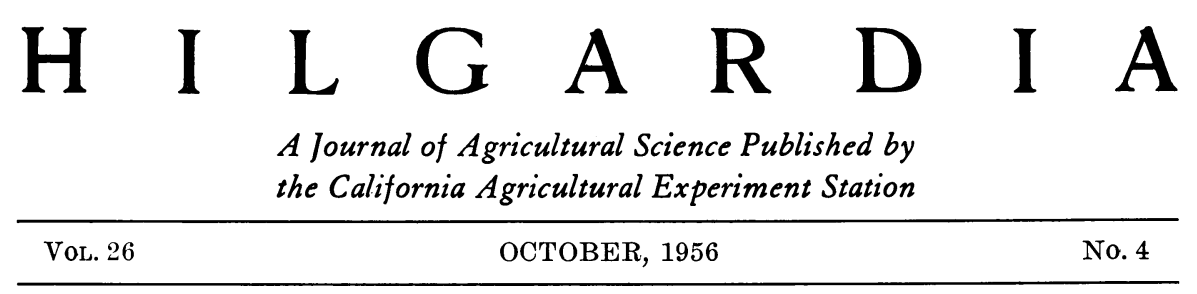

\section{EXPERIMENTAL STUDIES ON PREDATION:}

\section{Predation and Cyclamen-Mite Populations on Strawberries in California ${ }^{1}$}

\section{B. HUFFAKER ${ }^{2}$ and C. E. KENNETT ${ }^{3}$}

THIS PAPER has a twofold purpose: first, to present the results of field experiments in the use of predation to control a mite attacking strawberries in California, experiments which we hope will be a step toward filling the increasingly acute need to reach a balance between chemical and biological means of pest control; and second, but not least, to discuss the implication of the results for theories of population dynamies, particulary the role of predation.

The integration of two such distinct objectives may at times appear forced, for the discussion of population dynamies leads us far afield from the immediate problem; but both ecologists and entomologists may gain from such an attempt to bridge the gap between pure and applied ecology. Furthermore, details of the experiments and their setting are necessary to an understanding of the bearing of the results on theory.

\section{EXPERIMENTS WITH PREDATORY TYPHLODROMUS}

The work here reported is an experimental study of predation under field conditions. This study is the result of an attempt to develop a practical program for control of the cyclamen mite, Tarsonemus pallidus Banks, in strawberry fields in this state, by use of a native predatory mite, Typhlodromus cucumeris Oudemans, or Typhlodromus reticulatus Oudemans, or both. "The exploratory greenhouse experiments were conducted at Albany, the field experiments in the Santa Clara Valley.

${ }^{1}$ Received for publication August 15, 1955.

${ }^{2}$ Associate Entomologist in Biological Control in the Experiment Station, Berkeley.

${ }^{3}$ Principal Laboratory Technician in Biological Control in the Experiment Station, Berkeley.

${ }^{4}$ In these experiments the form present in any given field was not commonly determined. The mite is hereinafter referred to as the "predator" of the cyclamen mite or occasionally -to distinguish it from still other species of the genus-as Typhylodromus cucumeris; but this usage does not imply absence of $T$. reticulatus. 


\section{The Nature of the Problem}

The cyclamen mite is the most important pest of strawberries in California, a crop with an annual farm value of about $\$ 50,000,000$. No suitable chemical means for the control of the pest on this crop are known. Heat treatment of nursery plants, although effective at the time (Smith and Goldsmith, 1936), is no longer practiced since nursery stock is not now the source of most infestations. First-year plants are, during their early growth, sparse and open to the sun and wind-a condition not favorable to this pest. However, a survey in late 1953 in the Santa Clara Valley showed that nearly all fields had small foci of infestation by late fall after the first season's growth. From that period onward, the mite is a serious threat to berry production during the three crops years, the second, third, and fourth seasons, except as it is kept naturally under control by native Typhlodromus.

The present problem, even when clean planting stock is used, arises almost invariably

from a complex of circumstances, involving a closer association of fields and of grower activities conducive to rapid spread of the mite from field to field; a shift from a rather resistant variety, the Marshall, to more susceptible ones; and the destructive effects of recently developed chemicals on natural enemies of the mite,

as stated by Huffaker and Kennett (1953).

The problem is reciprocally related to infestations of other pests, twospotted mite, Tetranychus telarius (Linn.), and the strawberry aphid, Capitophorus fragaefolii Ckll., in particular. The former commonly causes damage only during the spring period in the major strawberry area and if not controlled by acaricides can cause damage just as severe as that caused by the cyclamen mite during midsummer and fall. If plants have suffered severe injury from two-spotted mite in the spring, vigor and nutritional qualities are impaired, summer growth is sparse, and the plants remain open to sun and wind. The microenvironment and food material are thus less favorable to subsequent cyclamen-mite populations. Furthermore, Typhlodromus occidentalis Nesbitt and Orius sp. may develop high populations in fields with high populations of two-spotted mite. These two predators, although more characteristically predators of the two-spotted mite, also prey on cyclamen mite, particularly if the latter occurs at high densities. Both, however, may prey on T. cucumeris, the effective predator of cyclamen mite. Presence of less specialized predators resulting from two-spotted mite infestations may, therefore, affect subsequent cyclamen-mite densities in either a positive or a negative way.

In its direct injury, the strawberry aphid is not commonly a serious pest of strawberry. Its seasonal abundance is largely during the periods in spring and late fall when the berries are not in high production, and the direct injury appears to be short in duration. High populations of aphids appear to compete very little with cyclamen mites. However, this aphid has been considered (Thomas and Marcus, 1953) as a vector of a virus-disease complex of strawberries, the etiology of which is not fully understood. Virus-weakened plants probably have a decreased physiological potential for development of 
high cyclamen-mite densities. In addition, the cyclamen-mite predator is known to feed on aphid honeydew, which is considered an important source of both nutrients and water during periods when prey densities are low. An alternate prey species, Tarsonemus setifer Ewing, which is harmless to strawberries and lives on moldy, dead leaves is also at times important in the economy of this predator.

The necessity for chemical treatments for two-spotted mites and, to a lesser degree, aphids, complicates the improvement of predatory control of cyclamen mite. This phase of the work has generally been conducted in conjunction with W. W. Allen of the Department of Entomology and Parasitology of the University of California. The objective has been to use chemicals which would give satisfactory control of these other pests, but not destroy too many of the predators of cyclamen mite, and to stock new fields with predators in order to reduce the costly time lag in appearance of effective predation.

Aphids are generally secondary to cyclamen mites and two-spotted mites. When chemical control is required, treatment with TEPP prior to stocking a field with predators often gives adequate control. After a field has come under biological control by predators, a single treatment with TEPP either during the spring or late fall periods of trouble, would not seriously interfere with cyclamen mite/predator balance because of the timing and limited toxicity of the material to the predators.

\section{Some Biological Attributes}

Habits and Requirements of the Mite. A female cyclamen mite deposits about three eggs per day for a period of 4 or 5 days. The males constitute only about 5 per cent of the adult population, reproduction being possible by parthenogenesis for successive generations (Smith and Goldsmith, 1936). The species is reproductively inactive during the colder winter months. Relatively small numbers of adult females, hidden in crevices and folds deep in the crown of the plant, constitute the overwintering population during normal years. The strawberry plant is unusually favorable for the mite's microenvironmental requirements, particularly in the coastal valleys of California, where extreme summer temperatures combined with excessively low humidities are uncommon. The many folds, crevices, and hairs characteristic of the young leaf shoots and blossoms prior to their opening and maturity furnish an ideal microenvironment for this mite: abundant food, maximum humidity and shelter, and protection from many general predators which might otherwise thrive on them.

Through its feeding, the mite prevents or retards elongation of leaf petioles and growth of leaflets, and may cause malformed leaflets which never fully open. Thus, to a degree, it is capable of prolonging the favorability of its own habitat. Nevertheless, the opening and maturing of new growth eventually forces the mites to seek new growth emerging at the crown position. Therefore, even in the absence of predation there is definite limitation to numbers. The continuing sequence of movement from old growth to new, accompanied by high mortality, imposes a marked restriction, so that the mite's high potential for reproduction is not realized even prior to conditioned unfavorableness of the plants, such as occurs after prolonged infestation. 
Predator-Prey Relations. The predator is admirably adapted to hold the densities of its prey at levels noninjurious to the strawberry plant. When cyclamen mites are abundant, its rate of reproduction is close to that of its prey-two or three eggs per day per female for a period of 8 to 10 days or more. Reproductive rate, however, is only a small asset, almost meaningless taken alone. Well-adapted capacities for searching, synchrony of environment and seasonal activity, and behavioral patterns and adaptations that are highly specialized to reduce prey densities and to survive at low prey densities play a far more vital role.

There are notable checks on the cyclamen mite (such as food and shelter limitations) other than predation at small foci on the same plant, which may prevent achievement of its reproductive potential at those points, while the predator may be relatively unchecked. Thus, a favorable ratio of predator to prey may be achieved fairly quickly. Once such a balance is achieved, overpopulation is not normally again attained even on the small foci because the predator is more capable of moving from leaf to leaf, and thus it cancels the reproductive power of its prey while its own is temporarily unhampered.

The predators may often be found secluded in the petiole sheaths at the base of the plant and are thus in position to readily capture surviving mites which must enter that area when moving to new leaf shoots. This predator has not exhibited cannibalism, a means of survival of many predators at very low densities of their prey species. Its utilization of honeydew of aphids or white flies, or possibly plant exudates, enables its survival at very low densities of its prey. So far as known, it is limited on cultivated strawberries to cyclamen mite and related tarsonemids for reproductive nutrients. It utilizes other materials only as supplemental food and for survival, and does not produce eggs when not feeding on regular prey. Hence, its density is directly and reciprocally geared to the density of its prey, but it is cushioned, without resort to cannibalism, against extermination through overconsumption of its prey. This enables it to recover quickly in numbers and to a point of adequate frequency of occurrence, so that it does not undergo oscillations of very wide amplitude in both space and time, such as those discussed by Nicholson (1954).

In this connection, physical barriers, representing a security threshold that results from the great heterogeneity in the microenvironment, seem to preclude actual extermination of the prey on any unit as large as an entire plant, or at least a group of adjacent plants. Hence, equilibrium is reached and a rough, although disturbed, balance at very low densities is characteristic.

The predators do not become established in very new fields, but delay their appearance until after the mite has become established. The foci of mite infestation, which appear in the late first year, "blossom" into serious infestations during the second year at about the time of greatest population ascent in June and July. Predators naturally invade the fields, a few being found even in the late first-year fields, but there is a definite lag which occasions various degrees of economic loss, especially during the second-year crop. Waves of cyclamen-mite damage from many or several spots, followed by "clean-up" by predators, are characteristic. Loss during the important second year may vary from relatively little to nearly complete. Very occasionally 
in Santa Clara Valley, a warmer area, and rather commonly in the cooler regions near Watsonville, California, where the industry is still new and sources of infestation by cyclamen mites are not so plentiful, infestations do not reach a troublesome stage until the third year. Action of predators consequently is delayed. Once "clean-up" by predators has been achieved, no case has been found where this pest has again become a serious problem during later years of this four-year crop, except where use of chemicals destroyed the predators.

\section{Experimental Approach and Population Estimates}

The approach in these experiments has been through altering a single environmental factor-manipulation of the predator population by artificially introducing the pest species and the predator species-and by using acaricides to eliminate or exclude the naturally occurring predators in control plots so as to encourage earlier predator-prey equilibrium at noneconomic levels of the pest.

Except for the greenhouse experiment on the nature of predator/prey oscillations, the experiments were carried out in commercial fields where the coöperating growers followed a suggested program for the control of twospotted mite; hence, they constitute a test of the compatibility of biological and chemical methods of control of these two strawberry pests in this area.

Aphid control did not prove necessary except in the greenhouse experiment; there spraying with nicotine was a compatible solution.

The specific data upon which this paper is based were obtained in 1953 and 1954. However, the basis of analytical discussion comprises experimental work done over a five-year period, partly covered in a preliminary way by Huffaker and Spitzer (1951) and Huffaker and Kennett (1953).

Estimating Cyclamen-Mite Populations. The method of partial census or sampling used in this study has varied somewhat according to the specific nature of certain experiments. The procedure was determined in a statistical manner. Some general aspects were stated by Huffaker and Spitzer (1951):

The population estimates must be reproducible within reasonable confidence limits. In this study, this problem has been complicated by many factors. The estimates can be made only by removing a portion of the population. The most characteristic plant part for use as the sample item is the unopened, rolled leaf-shoot, and such leaves in the proper stage for sampling are always few in number and at certain seasonal periods are very scarce. The logical plant unit for sampling would otherwise be the individual strawberry plant, but since it was learned that only one or two leaflet units can be taken with any hope of taking repeated samples from the same plant at the required intervals, groups of plants had to be used as the plant unit of replication. Fortunately, it was found that the variation in mite numbers was low between the three leaflets of a leaf, and therefore greater economy in labor and less disturbance of the populations was experienced by taking only one of the three leaflets of a given leaf. It was also found that in a fairly late stage of an infestation the variation between leaflets was of about the same statistical order whether five leaflets were taken from five different but adjacent plants or whether one leaflet was taken from each of five different leaves of the same plant.

Hence, a group of fifteen adjacent plants became the plant unit for replication.

In arriving at sample size, a total of thirty leaflets was taken, one each 
from thirty plants. By randomized selection of the leaflet results from groups of variously sized lots, it was found, by drawing twelve successive randomized combinations of each size group, that only when twenty-four leaflets were used was the standard error of the means sufficiently low so that reproducibility was achieved. However, the sample size was increased to thirty leaflets per plot or position.

The method of estimating populations has been more satisfactory for the cyclamen mite than for the predator. Cyclamen-mite densities were relegated to size classes, and after some practice, and by use of occasional counts when densities appeared to be borderline, estimates of prey populations were found to be reproducible and adequate. Estimates consistently run from 30 to 40 per cent lower than actual counts. The relegation to size classes for the population of each leaflet has been on the following basis: $0 ; 1$ to 5 , or a nil density; 6 to 20 , or low density; 21 to 50 , or medium density ; 51 to 100 , or high density; and 101 or over, as very high density. Only in 1954 was a category above 100 utilized. It has been found that the estimate of 75 for averaging purposes (51 to 100) was far too low for the highest densities encountered. For averaging purposes, the figures $0,3,13,35,75$, and 150 were used to represent these range classes. The requirements in the practical operation of this program did not call for or permit actual counting of the prey species.

Estimating Predator Populations. With regard to the predator populations, it was found by trial analysis that frequency of occurrence-that is, enumeration of the number of leaflets, among the thirty taken, having one or more predators-is a more reproducible estimate than is obtained from the numbers counted in the sample. In an area where predators were in abundance (a mean of means of 27.8 per thirty leaflets, based on twelve separately randomized lots of thirty leaflets each), it was found that the mean of means for frequency, although lower, at 15.6, had a range of only 6 and a rule-ofthumb standard deviation of 2 , while the range for the actual count was 20 with a rule-of-thumb standard deviation of 7 . Particularly at low populations, that is, those at equilibrium, the concept of frequency distribution was considered more important in this study. Moreover, since the quantitative order of changes at high populations is easier to follow and to interpret than are those at the low levels, the frequencies of predator occurrence have been used. For example, the occurrence of large numbers of predators on a given leaf or strawberry plant is not indicative of predator action throughout the sample unit (the group of thirty leaflets) and is not as closely related to capacity to increase intensity of action quickly with increase in prey densities. The predators are very small and have limited powers of movement even though they are much more active than their prey.

When populations are low, the sample size has been too small with respect to the predators. In the absence of knowledge in advance of population densities of the plots to be sampled, the sample size would have to be such as to be adequate for the lowest densities. However, since the low densities were normally so very low as compared with the high densities, and consistently so from one sample date to another, a standard sample size of thirty leaflets was adopted. 
Validity of Methods and Procedures. The enormous contrast between compared plots as to prey densities, the frequency of sampling (each sample being a curvilinear check on the previous and subsequent samples) and the fact that differences between estimates made in this manner and actual counts on the same sample were uniform and dwarfed by the differences between the experimentally compared plots (that is, predator-present vs. predator-free plots), seem to be ample evidence for the placing of general reliance on recorded estimates of prey densities. The over-all conclusions in any case seem inevitable.

The method of evaluating predation has consisted basically of employing an acaricidal check method for removing predators from one plot of two paired field plots, and either allowing natural predators to enter the other unaided, or artificially stocking it initially with predators.

As a significant evaluation, a check was also made on the "check method" by mechanical hand-removal of predators from one group of plants, so as to eliminate the possible alternative explanation that the chemical used in destroying the predators in the field studies may have "stimulated" the cyclamen mite, either directly or indirectly, to greater abundance. The latter technique was reported by Huffaker and Kennett (1953). They concluded, "The results from tests on hand-removal of the predators removed any objection to the interpretations [of effective control] on the basis that parathion might itself favor increase of cyclamen mite."

Samples were taken on one occasion at night for comparison with samples from the same plots taken during daytime because of the known diurnal pattern of movement of many species of mites, both predatory and phytophagous. The object was to learn if significant predation occurs by species not encountered by daytime sampling. Such was not the case, the counts of all faunal elements being very similar.

The experimental design and objectives of each phase of experiment, as well as any basic departures from the methods as herein outlined, will be discussed with the respective experimental data.

\section{Summary of Earlier Tests}

Data obtained from 1950 to 1952, inclusive, published by Huffaker and Spitzer (1951) and Huffaker and Kennett (1953), form an integral part of the experimental evidence, and their results may be reviewed briefly. Work was first done in 1950 in third- and fourth-year fields because of grower experience of much less cyclamen-mite severity in older berry fields as compared with that in second-year fields. It was desired to learn if the predators in those fields accounted for the condition. In the former paper, results on four pairs of plots in third-year fields, one plot of each pair with natural predator populations, the other predator-free, were reported. The authors concluded, "The results, though not excluding the possibility of a chemical or residual 'stimulative' influence, were sufficiently logical as to suggest strongly a definite control of its host [prey] by the predator."

During 1951 and 1952, results from twenty pairs of field plots, in which one plot of each pair was kept predator-free and one had predators, were 
obtained (Huffaker and Kennett, 1953). These included second-, third-, and fourth-year berries of six different varieties in plantings of many different operators throughout the Santa Clara County strawberry district. The field population studies conclusively showed that the predators

exert very effective control of the cyclamen mite in third- and fourth-year fields in this area when their activities are not inhibited by detrimental chemical treatments used for control of other pests. Control in second-year fields is somewhat erratic due, it is felt, to the lag in appearance of predators and to the more vigorous (chemical) treatment practices which are applied to the second-year crop.

Either hand-removal or chemical removal of predators resulted in striking increase in cyclamen mites, as compared to the predator-present controls. Increase in berry yield due to the action of the predators in the predatorpresent control was in one test seven-fold. The predator maintained marked control of the prey population both in old weakened fields and when seasonal and berry-culture conditions were not conducive to the highest densities of cyclamen mite, such as would be necessary for demonstration of the most striking effects.

\section{Greenhouse Test}

Methods. On April 8, 1952, seventy-two potted plants were arranged in two randomized groups on greenhouse benches. Each group had been treated in January in order to destroy all predators. By April the prey species had developed light infestations. The predator had recovered to low density levels. Parathion was again applied on April 8 to control the predators on one group after the first samples were taken. This group is hereinafter referred to as the "predator-free" group, the term meaning relative but not complete absence of predators at all times. Three additional predators were added to each plant of the predator-stocked group on that date. The directly compared predator-present/predator-free paired groups were sampled at approximately 11-day intervals until April 14, 1953, at which time the plants in the predator-free group had become badly weakened and some were dying. The experiment consequently was terminated.

The strawberry plants were cultured in a greenhouse maintained at temperatures of $65^{\circ} \mathrm{F}$ at night; daytime temperatures occasionally rose during summer, as a result of insolation and inadequate cooling controls, to $80^{\circ}$ to $85^{\circ}$. Generally, however, temperatures were fairly even at a daily mean of about $70^{\circ}$. Relative humidity was not controlled, but the humidities of the special leaf-shoot habitats of the cyclamen mite are naturally high beneath the lush growth of the strawberries, which were irrigated frequently.

The few predators shown in figure $1 C$ in the predator-free group at the end of June and early July were taken from only three of the thirty-six plants. Retreatment on July 18 with parathion became necessary, therefore, in order to reëstablish a truly predator-free group. Retreatment was again necessary on November 18, but not thereafter because no predators were encountered after that date. Genite, a material which does not harm either the predator or prey, was used to control two-spotted mites on both groups of plants. 
Control with Oscillations. The preference of Allee et al. (1949) for the term "fluctuation" is well taken. However, the changes in populations of prey species and predator species as shown in figure 1 are such that a reciprocal relation of an oscillatory nature is indicated. These data furnish the best example of long-term, undisturbed interaction. The field data in no case appear to controvert these remarks.

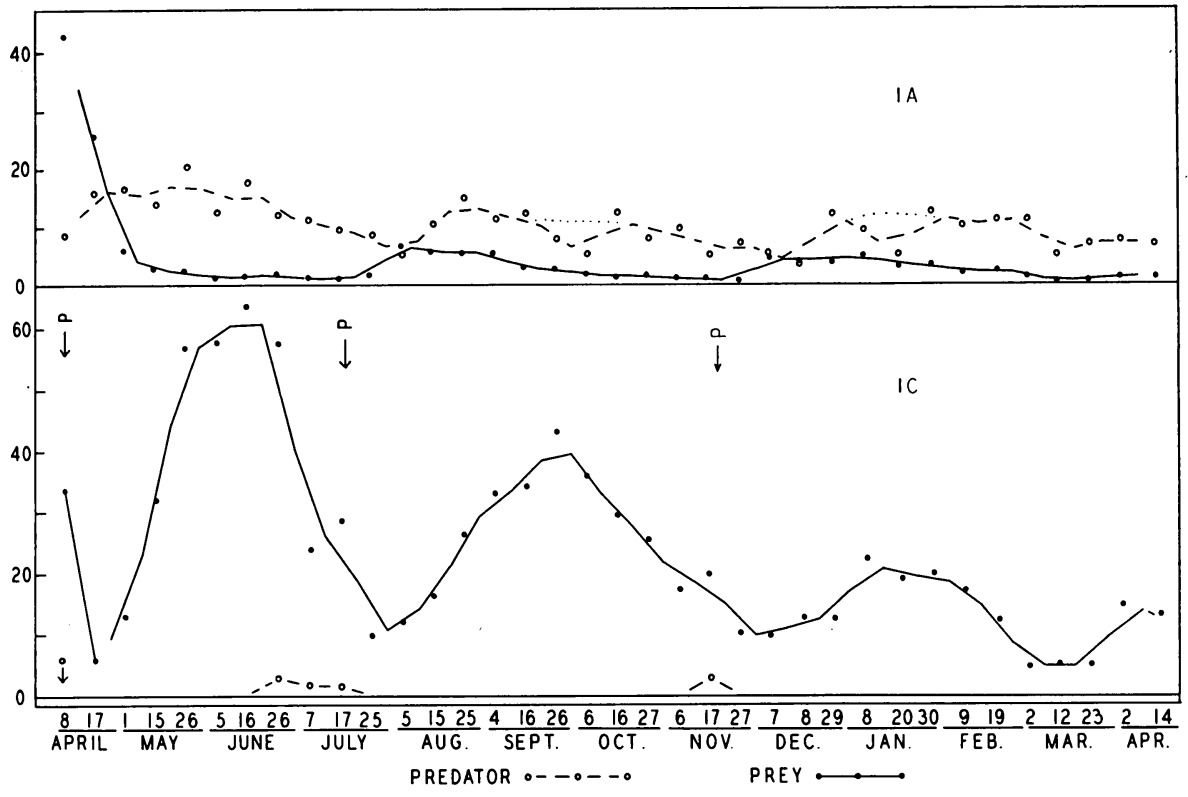

Fig. 1. 1952-1953. Greenhouse plots: Changes in densities of Tarsonemus pallidus (=prey) in predator-present and predator-free plots, and Typhlodromus (=predator) frequencies. One pair of plots; one plot (1A) with predators, the other kept predatorfree (plot 1C). The T. pallidus in the two plots are plotted on a per-leaflet basis. The predator frequencies express the number of leaflets among 36 which had one or more Typhlodromus. " $p$ "s by arrows indicate dates of parathion treatment.

At the initiation of the experiment, cyclamen-mite and predator densities were subequal in the groups shown in figures $1 A$ and $1 C$. Both prey populations at that time were in a crash phase as a result of predator action. The diminished predator effect at that time, resulting from predator destruction by parathion, was offset by the temporary depressive effect of parathion's killing some of the prey species. Some influence of the previous predation on eggs probably was registered as part of this crash effect, since the eggs were not counted in the population densities. From this point of simultaneous crash in the two populations-a holdover from equivalent history prior to April 8-there is never again any similarity whatever in the prey densities of the two groups. Instead, the unequivocal contrast persisting thereafter was always a measure of the regulatory action of the predatory Typhlodromus. For reference, contrast the magnitudes of cyclamen-mite, or prey, densities in figures $1 A$ and $1 C$. 


\section{Predator Stocking of First-Year Fields}

Methods. During the fall of 1953, plots were established in San Martin in the Santa Clara Valley, with the purpose of learning something of the pattern of movement of mites and predators, but primarily to establish the value of stocking early mite infestations with predators, so as to achieve early equilibrium and, consequently, control of the prey species. Six foci of infestation were located in several test varieties of berries. These were considered the "zero" distance, designated "A" plots. Two of these, 1A and 3A, of figure 2, were stocked with predators on September 30 ; and one, $5 \mathrm{~A}$, figure 2 , on October 28 . The other three $\mathrm{A}$ plots, $2 \mathrm{~A}, 4 \mathrm{~A}$, and $6 \mathrm{~A}$, had no predators

TABLE 1

ARRANGEMENT OF FIRST-YEAR FIELD PLOTS

\begin{tabular}{|c|c|c|c|c|c|}
\hline \multirow{2}{*}{ Text figure } & \multirow{2}{*}{$\begin{array}{c}\text { Replicate } \\
\text { no. }\end{array}$} & \multicolumn{4}{|c|}{ Replicate no., position and fig. designation } \\
\hline & & $\begin{array}{c}\text { Zero } \\
\text { distance }\end{array}$ & $\begin{array}{l}3 \text { rows lateral } \\
\text { to zero dist. }\end{array}$ & $\begin{array}{c}25 \text { feet } \\
\text { down row }\end{array}$ & $\begin{array}{c}75 \text { feet } \\
\text { down row }\end{array}$ \\
\hline $2 \ldots \ldots \ldots$ & 1 & $1 A^{*}$ & $1 \mathrm{C}$ & $1 \mathrm{~B}$ & 1D \\
\hline None........ & 2 & $2 \mathrm{~A}$ & $2 \mathrm{C}$ & $2 \mathrm{~B}$ & $2 \mathrm{D}$ \\
\hline None............. & 4 & $4 \mathrm{~A}$ & $4 \mathrm{C}$ & $4 B$ & $4 \mathrm{D}$ \\
\hline None............. & 6 & $6 \mathrm{~A}$ & $6 \mathrm{C}$ & $6 \mathrm{~B}$ & $6 \mathrm{D}$ \\
\hline
\end{tabular}

* Predators added only to $1 \mathrm{~A}, 3 \mathrm{~A}$, and $5 \mathrm{~A}$ above.

added at any time. Six B plots were set up 25 feet down row from the corresponding A plots. Six C plots were set up three rows lateral to the six A plots and six D plots were set up 75 feet down row from the A plots. The arrangement is shown in table 1 .

The B, C, and D positions were otherwise random as to known occurrence of cyclamen-mite infestations.

Occurrence of Predators and Prey. The degree to which first-year fields may have developed infestations by the end of the first growing season (October) is indicated by the fact that 5,4 , and 5 , respectively, of each of the six plots at the lateral (C) positions, the 25-foot (B) positions and the 75 -foot (D) positions, were infested at the beginning of the experiment, although only very lightly so in most instances. Hence there was no test of the relation between proximity to known centers of cyclamen-mite infestation and earliness of infestation. For that reason the 75-foot positions were later dropped from the experiment. Other evidence has also indicated that incipient cyclamen-mite infestation is general in Santa Clara Valley in a majority of late season first-year plantings.

On the other hand, the predators were not nearly so regular in occurrence in the field at the initiation of the experiment. There was a fairly rapid establishment of predators in the three plots, $1 \mathrm{~A}, 3 \mathrm{~A}$, and $5 \mathrm{~A}$, where they were added, for they were taken in those plots at the first or second samplings subsequent to stocking. None of the plots which were not stocked showed any 

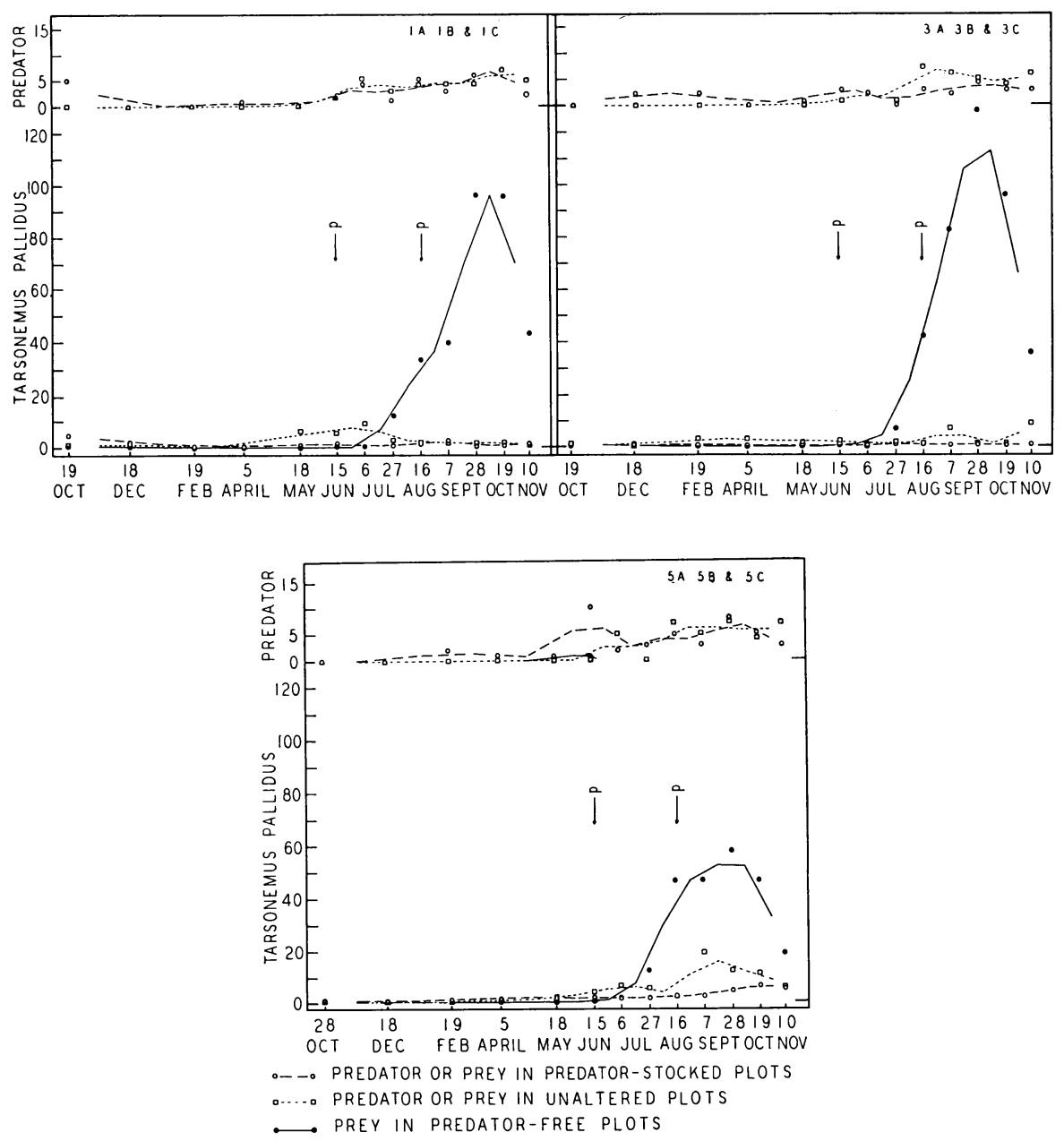

Fig. 2. 1953-1954. First-year plantings: $1 \mathrm{~A}, 1 \mathrm{~B}$, and $1 \mathrm{C} ; 3 \mathrm{~A}, 3 \mathrm{~B}$, and $3 \mathrm{C} ; 5 \mathrm{~A}, 5 \mathrm{~B}$, and 5C; experimental varieties at San Martin. Changes in densities of Tarsonemus pallidus (= prey) in predator-stocked, predator-free and unaltered plots, and Typhlodromus (= predator) frequencies. Three triplicated series; one plot of each series predatorstocked, one unaltered and one kept predator-free. The T. pallidus in the three plots of a series are plotted on a per-leaflet basis. The predator frequencies in the predator plots express the number of leaflets among thirty which had one or more Typhlodromus. "p"s by arrows indicate dates of parathion treatment in the $\mathrm{C}$ plots.

definitely or persistently established colony of predators prior to May of the following year, although in plots $3 \mathrm{D}, 6 \mathrm{C}$, and $6 \mathrm{~B}$ a single predator was taken in each case, either in December or October. Subsequent samples showed none for several successive sample periods.

There was no appreciable movement of predators from the stocked positions to the plots three rows to the side or either 25 feet or 75 feet down row; that is, proximity to the stocked plots did not add significantly to the earli- 
ness of predator establishment in the plots at those positions. Natural dispersion of predators throughout the field occurred in adequate numbers in May, June, and July of the following year to minimize the importance of any predators received naturally from the stocked positions.

Since plots $2 \mathrm{~A}, 2 \mathrm{~B}, 2 \mathrm{C} ; 4 \mathrm{~A}, 4 \mathrm{~B}, 4 \mathrm{C} ; 6 \mathrm{~A}, 6 \mathrm{~B}, 6 \mathrm{C}$; and 1D, 2D, 3D, 4D, 5D, and $6 \mathrm{D}$ are not directly of use in the present discussion, having been established in order to obtain information on movement, the data from those plots are not presented graphically in this paper.

Resulting Control in Second-Year Berries. Stocking of predators during the fall of the first growth year resulted in control of cyclamen mites throughout the economically important second-year season. This was achieved by early establishment of predator/prey equilibrium before the season of population surge of the prey species. Once equilibrium was achieved, and in the absence of detrimental chemical treatments, no degree of conduciveness to prey-species fecundity seemed enough to change seriously the level of equilibrium. In spite of changes in predator population densities, sometimes hard to explain in the absence of abundant specific prey, the cyclamen mite was held at levels entirely noneconomic in plots $1 \mathrm{~A}, 3 \mathrm{~A}$, and 5A. Maximal densities of cyclamen mites per leaflet during the summer of 1954 were $3.1,0.9$, and 6.5 , respectively. On the other hand, the corresponding predator-free plots $1 \mathrm{C}, 3 \mathrm{C}$, and $5 \mathrm{C}$ developed prey densities highly injurious to the crop, with peak populations of $93.5,128.6$, and 57.4 , respectively.

A comparison between plots $1 \mathrm{~A}, 3 \mathrm{~A}$, and $5 \mathrm{~A}$ and plots $1 \mathrm{~B}, 3 \mathrm{~B}$, and $5 \mathrm{~B}$ (fig. 2) (the latter were permitted natural immigration of predators but had none added) revealed a definite difference in prey densities in relation to the previous predator history for the respective plots. Natural build-up of predator populations was adequate shortly after the initial spurts in prey populations to curtail the development of very high densities, such as characterized the predator-free, or C plots, 1C, 3C, and 5C of figure 2 .

It may be seen that in plots $1 \mathrm{~B}, 3 \mathrm{~B}$, and $5 \mathrm{~B}$ the prey population levels attained were intermediate between those of the comparable predator-free and predator-stocked plots, although much nearer the condition in the latter. This is because the natural predator establishment in the area during that season was unusually early, but a delay of one or two months longer might well have been enough to have allowed cyclamen-mite densities to surge to maximal levels and injury before natural predator populations would have sufficed to control the infestations.

Consideration of certain segments of ascendance in population in the absence of either predators or chemical-treatment history, in the various plots which had delayed entry of predators, lends further support to results obtained by Huffaker and Kennett (1953), by use of hand-removal of predators, to the effect that the parathion used as a chemical "check method" of evaluation did not itself cause the marked increases in cyclamen-mite densities observed when that chemical was used. For example, plots $1 \mathrm{~B}$ and $5 \mathrm{~B}$ (fig. 2) and plots $2 \mathrm{~A}$ and $4 \mathrm{~A}$ (not presented) had delayed entry of predators and rates of population increase in April, before the entry of predators, which were just as pronounced as that shown in the initial periods of increase subsequent to chemical treatment in June for the $\mathrm{C}$ plots, that is, $1 \mathrm{C}, 3 \mathrm{C}$, and $5 \mathrm{C}$. 
These data verify those from the greenhouse experiment in every general respect, although correlative aspects of predator/prey populations in plots having predators are not as close chronologically. The longevity characteristic of the predator population, even in trough positions when prey densities are at their lowest, is evident. Upon the approach of fall and winter under these field conditions, the predator species does not show the marked decline that is characteristic of the prey species. The latter declines sharply in numbers encountered on young shoots during early winter, partly because of a movement downward to points of concealment from sampling. On the other hand, the predator population increases as the reproductive season progresses, offset only partially and belatedly by declines in prey densities. The population passes the winter in the adult state, and mortality during the late winter and spring is heavy, despite utilization of alternate foods. Even in old infestations, cyclamen mites as a rule are very low in density from December until April, and in some places until May or June. However, relatively earlier increases in mites have been observed during years of exceptionally mild winters or unseasonably early summers.

Actual counts of populations of cyclamen mites, or prey species, on the sample leaflets in the predator-stocked, unaltered plots, and predator-free plots-that is, comparison of $1 \mathrm{~A}$ with $1 \mathrm{~B}$ and $1 \mathrm{C}$; $3 \mathrm{~A}$ with $3 \mathrm{~B}$ and $3 \mathrm{C}$; and $5 \mathrm{~A}$ with $5 \mathrm{~B}$ and $5 \mathrm{C}$-were made on September 7 so as to permit a critical statistical analysis of differences at a season that was representative of high infestations. Upon pairing the data appropriately for September 7, the results were 92,21 , and 57 , respectively, for the predator-stocked plots, $1 \mathrm{~A}, 3 \mathrm{~A}$, and $5 \mathrm{~A}$; and 1,132, 2,480, and 1,392, respectively, for the predatorfree plots, $1 \mathrm{C}, 3 \mathrm{C}$, and $5 \mathrm{C}$. The differences were significant. Viewing these data in the light of extensive chronological population estimates throughout several seasons, with the data lining up in similar manner in all cases and with significance greatly exceeding the 1 per cent level, there is no room for doubt concerning significance of differences between the two experimental conditions.

\section{Predator Stocking of Second-Year Fields}

Methods. In April of 1953, two or three predators per plant were added to plots in ten new fields or sections of fields in the Santa Clara Valley that were just starting their second year of growth. Check plots were arranged on each side of the plots. Predators were not added nor removed in one of the check plots, although normal grower field practices were continued, including primarily the grower's use of Aramite or TEPP or both for control of twospotted mite during the spring months. The objective was to gain knowledge of the pattern of natural predator invasion and the resultant control under such treatments. The other check plot was the acaricidal check plot in which predators were kept out by use of parathion. Hence, there was again the direct comparison between predator-free and predator-stocked plots and an intermediate condition characteristic of normal grower practices. That year predators entered the second-year fields very early, the fields being very close to older ones, which were thus near at hand as a source for predator invasion. In some years the natural predator invasion was more delayed and more 


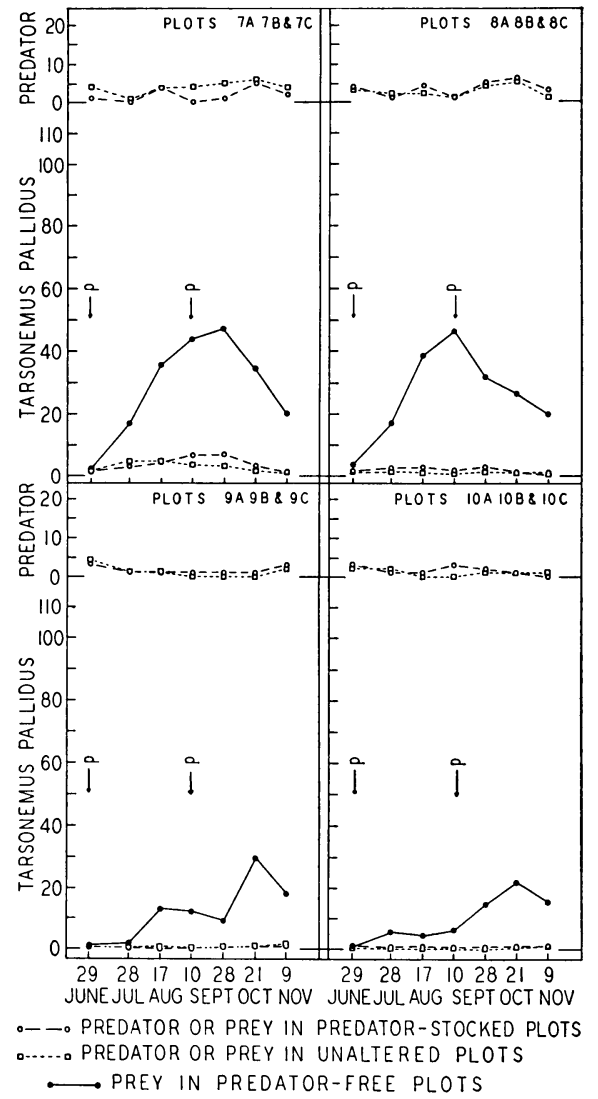

Fig. 3. 1953. Second-year plantings: $7 \mathrm{~A}, 7 \mathrm{~B}$, and $7 \mathrm{C} ; 8 \mathrm{~A}, 8 \mathrm{~B}$, and $8 \mathrm{C}$, Lassen at Madrone; $9 \mathrm{~A}, 9 \mathrm{~B}$, and $9 \mathrm{C} ; 10 \mathrm{~A}$, 10B, and 10C, J-7 at Madrone.

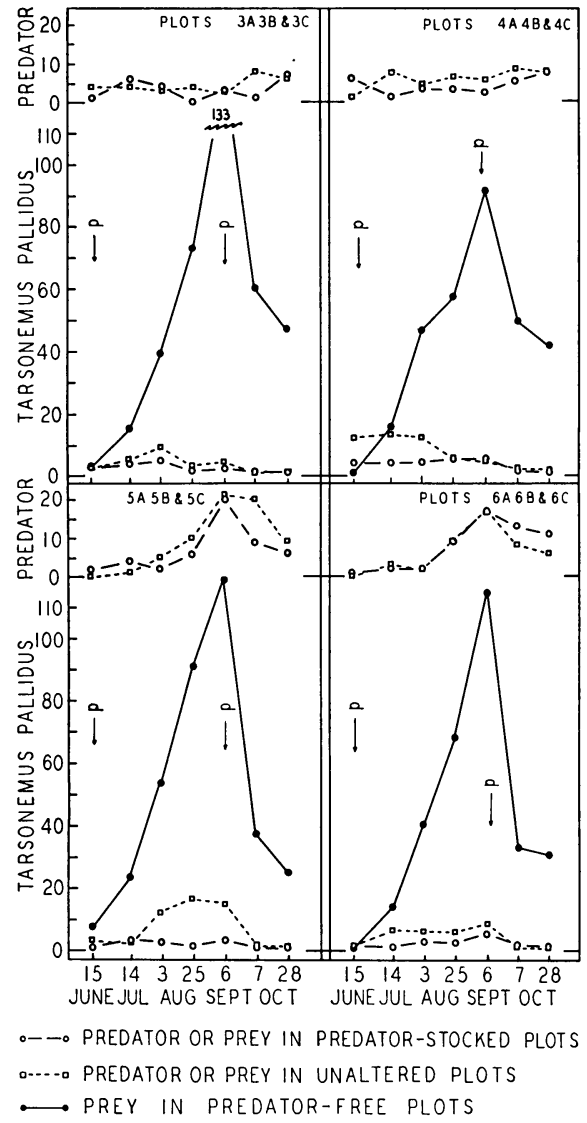

Fig. 4. 1953. Second-year plantings: $3 \mathrm{~A}, 3 \mathrm{~B}$, and $3 \mathrm{C} ; 4 \mathrm{~A}, 4 \mathrm{~B}$, and $4 \mathrm{C}$, Shasta at Morgan Hill; 5A, 5B, and $5 \mathrm{C} ; 6 \mathrm{~A}, 6 \mathrm{~B}$, and $6 \mathrm{C}$, Shasta at Edenvale.

Changes in densities of Tarsonemus pallidus (= prey) in predator-stocked, predator-free and unaltered plots, and Typhlodromus (= predator) frequencies. Eight triplicated series: one plot of each series predator-stocked, one unaltered, and one kept predator-free. The T. pallidus in the three plots of a series are plotted on a per-leaflet basis. The predator frequencies in the predator plots express the number of leaflets among thirty which had one or more Typhlodromus. " $p$ "s by arrows indicate dates of parathion treatment in the C plots.

erratic, and the control exhibited in second-year fields in the absence of predator stocking was very much less effective than was the case in these plots (Huffaker and Kennett, 1953).

Resulting Control in Second-Year Fields. The conclusions from the data, plots $3 \mathrm{~A}, 3 \mathrm{~B}$, and $3 \mathrm{C} ; 4 \mathrm{~A}, 4 \mathrm{~B}$, and $4 \mathrm{C} ; 5 \mathrm{~A}, 5 \mathrm{~B}$, and $5 \mathrm{C} ; 6 \mathrm{~A}, 6 \mathrm{~B}$, and $6 \mathrm{C} ; 7 \mathrm{~A}$, $7 \mathrm{~B}$, and $7 \mathrm{C} ; 8 \mathrm{~A}, 8 \mathrm{~B}$, and $8 \mathrm{C} ; 9 \mathrm{~A}, 9 \mathrm{~B}$, and $9 \mathrm{C}$; and $10 \mathrm{~A}, 10 \mathrm{~B}$, and $10 \mathrm{C}$, of figures 3 and 4 , are in complete agreement with the results from stocking first-year fields, previously discussed. 
It appears obvious that predator-stocking can be done during the spring of the second year, a time when it is more practical from an operational viewpoint. In each of these cases there was complete economic control of the prey species. In plot $5 \mathrm{~B}$, the natural predator population was very low on June 15 and July 14; hence, a subsequent increase in cyclamen mites occurred in Angust in that plot-a demonstration of a more definite intermediate condition between the predator-stocked and predator-free plots than existed in many of the triplicated series. Some of the plants had high prey populations, the predators having been erratically distributed until August, when, as a result of abundant food, they increased to a higher general level than in the predator-stocked plot; they then reduced the rather mild infestation to a condition of no economic importance. In this connection, although the predator densities in the unaltered plots were often as high as those in the predator-stocked plots at a given time, the more even pattern of distribution and the persistence at low densities during the early summer, as a result of early spring stocking, seemed, in every case, to account for more consistent economic control, despite the fact that the control in the unaltered plots was also good, if sometimes more delayed.

Plots $11 \mathrm{~A}, 11 \mathrm{~B}$, and 12A, 12B (fig. 5) were disturbed by the grower's use of materials not intended for use in the A plots and not commonly employed by strawberry growers at that season for the B plots. The berries were interplanted between rows of young pear trees. The grower was to cover the A plots at the time that he applied chemicals. However, when he treated the pears he ignored the drift onto the berries, apparently thinking it to be unimportant. The counts showed that on the two dates subsequent to the treatment with DDT and TEPP (shown by an arrow labeled "c" in the illustrations), there was a resultant near-absence of predators in $11 \mathrm{~B}$ and $12 \mathrm{~B}$ until late September. This was not the case in other fields. A similar detrimental effect also occurred on the predators in plots $11 \mathrm{~A}$ and $12 \mathrm{~A}$, but the period was not quite as prolonged, possibly because of a more even distribution and the existence of greater numbers of predators in the A, or predator-stocked plots at the time of the treatment. It can be seen that there were very definite spurts in prey population just after the chemical treatment, although the peaks achieved were not as high as those of the predator-free plots $11 \mathrm{C}$ and 12C. This condition was obviously due to the effective predation before treatment and during August and September, after the detrimental treatment effect had lessened. The plots represent the only case where predator stocking, either during the late first-year or early second-year, has not resulted in complete economic control of the prey mite, the reason being apparent.

It is surprising that the addition of only two or three predators per plant would make it possible to demonstrate consistently sharp contrasts in prey populations and complete economic control. This occurred regardless of whether a given variety of berry, for example, variety J-7, shown in plots $9 \mathrm{~A}, 9 \mathrm{~B}$, and $9 \mathrm{C}$, and $10 \mathrm{~A}, 10 \mathrm{~B}$, and $10 \mathrm{C}$ of figure 3 , had the capacity to support only very low peak densities of the prey, or whether it was capable of supporting, in the absence of predation (plots $3 \mathrm{C}$ and $5 \mathrm{C}$ of fig. 4) densities as much as 100 or more times that which occurred when predators were present. 


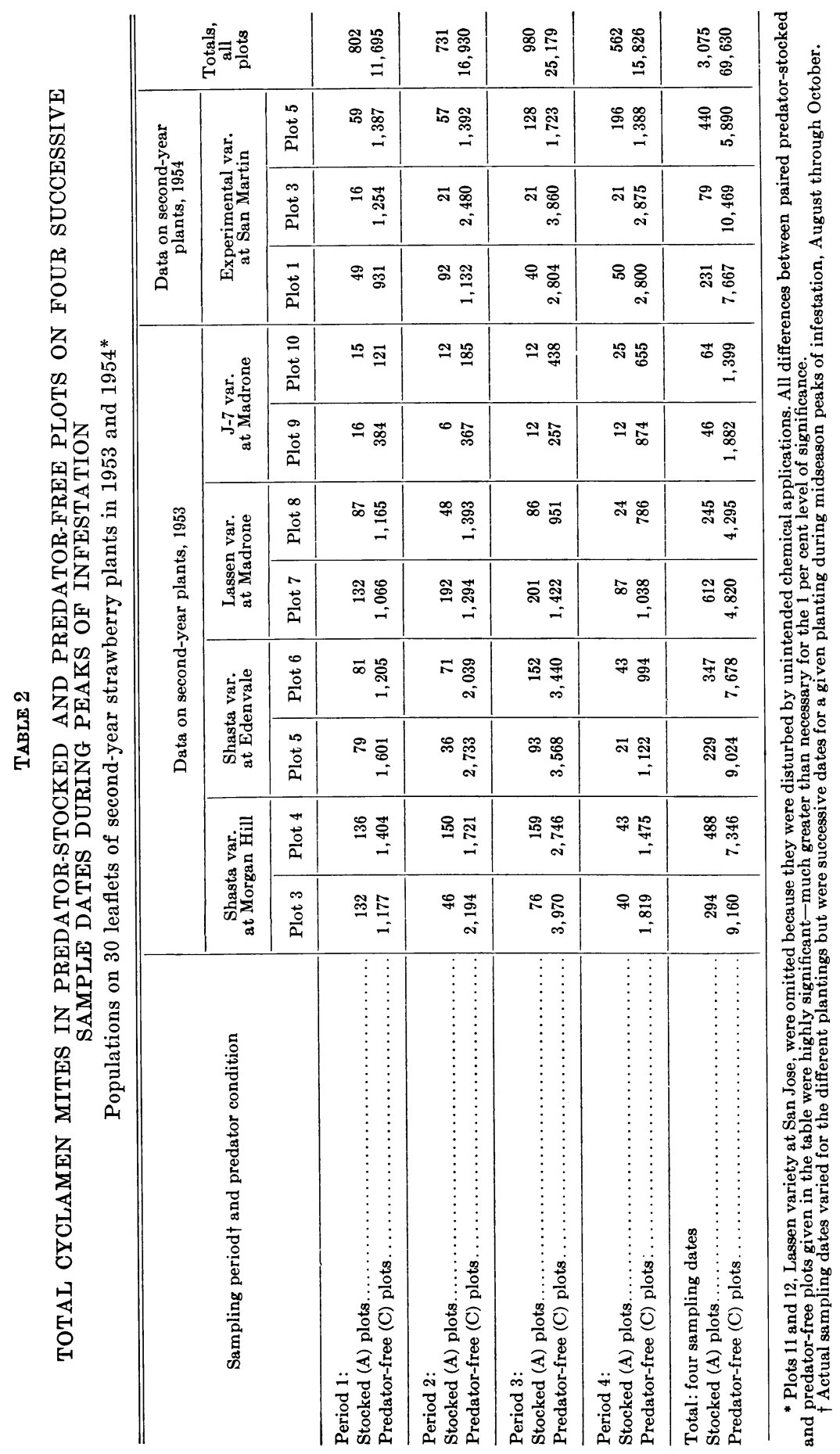


The experimental results from both the first- and second-year fields have been tabulated in combined form in table 2, excluding only the plots of figure 5 , those disturbed by unintended chemical application. The prey populations on four successive sampling dates during the midseason of highest infestation for eleven paired-plot series are presented. Inclusion of data either earlier or later seasonally would serve no purpose and merely complicate the analysis, since this mite is characteristically low in numbers early in the summer and declines again in the fall, irrespective of predator condition. The total for the predator-free condition was 69,630 , as compared with 3,075 for the predator-present condition.

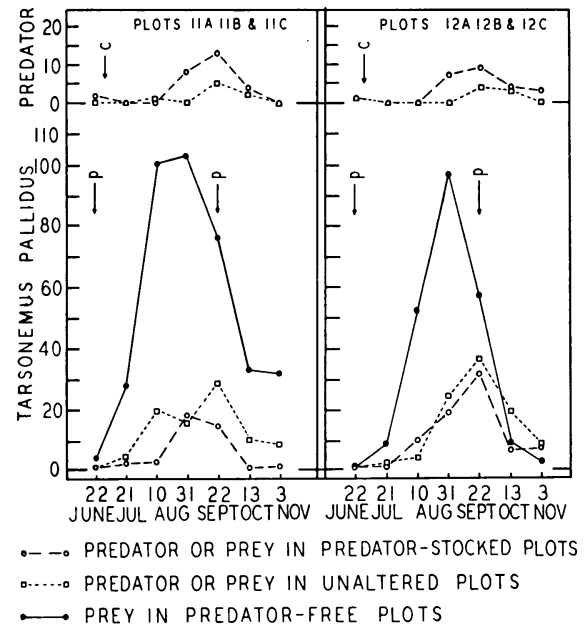

Fig. 5. 1953. Second-year plantings: $11 \mathrm{~A}, 11 \mathrm{~B}$, and $11 \mathrm{C} ; 12 \mathrm{~A}, 12 \mathrm{~B}$, and $12 \mathrm{C}$; Lassen at Cupertino.

Changes in densities of Tarsonemus pallidus (=prey) in predator-stocked, predator-free and unaltered plots, and Typhlodromus frequencies. Two triplicated series; one plot of each series predator-stocked, one unaltered, and one kept predator-free. The $T$. pallidus in the three plots of a series are plotted on a perleaflet basis. The predator frequencies in the predator plots express the number of leaflets among thirty which had one or more Typhlodromus. "p"s by arrows indicate dates of parathion treatment in $\mathrm{C}$ plots. "c"s by arrows indicate the date of unintended grower treatment.

\section{Problems in Commercial Application}

Should Plants Be Artifically Infested with Cyclamen Mites? The results from these studies have been so encouraging as to indicate the possible use of deliberate infestation of new plantings with the pest mite before the periods of highest yield and greatest loss from serious cyclamen-mite infestations, as a means of achieving earlier than normal equilibrium. Smith and DeBach (1953) stated,

Theoretically it would appear possible, therefore, that when hosts are abnormally scarce artificial infestation of plants in the field with the host insect would serve to synchronize parasite-host or predator-prey populations in such a way as to bring about effective biological control.

This approach is akin to certain types of immunization of animals against losses from disease by controlled vaccination with virulent pathogenic agents, according to a pattern whereby the period of disease is controlled and its economic severity greatly reduced. An example is that of fowl pox of poultry (Bunyea, 1942, p. 981).

Can Predator Stocking Be Done Economically? Tests are being made on the use of clippings from normal winter pruning of berries. Clippings from fields that have predators always bear predators and cyclamen mites. Growers 
are reluctant to accept the introduction of cyclamen mites into their fields. It might prove feasible to obtain from these clippings predators that have been separated from the cyclamen mites. However, cyclamen mites must be rather generally present in the new plantings if the predators to be added are to survive and if any good is to be derived. Both components of the ultimate equilibrium should be introduced in order to obtain quick and satisfactory results.

Aramite combines effective control of two-spotted mite with very low toxicity to cyclamen-mite predators. Chemical treatment necessary for aphid control, as well, may prove to be compatible with predator control of cyclamen mite. BHC has shown some possibilities for this purpose. Also, Wilcox and Howland (1955) obtained control of this pest in southern California by use of a 4 per cent nicotine dust. Nicotine sprays are known to interfere little, if at all, with Typhlodromus and, probably, dusts would not be much different.

Whether this procedure can be economically done on a large scale, whether it will prove compatible with control of other pests, and whether it will be accepted by the industry remain to be seen.

\section{ECOLOGICAL SIGNIFICANCE AND THEORIES}

\section{Considerations in Economic Entomology}

To many entomologists, problems of instrumentation and techniques, and the evaluation of temperature, humidity, light, and other similar environmental features as influences upon reproductive and behavioral phenomena of individuals, removed from the pressures and the variables that are characteristic of excessive numbers in complex ecosystems, have constituted the sphere of ecology. There has resulted a consequent overemphasis of mortality occasioned by meteorological factors or by the use of insecticides, for example. Important as these studies are, the problems of the economic entomologist are essentially problems of population dynamics, involving not individuals but groups, and not single factors acting independently, but many factors acting collectively and simultaneously, with a change in one factor occasioning compensating changes in others, or acting upon or in interaction with others.

A number of insect ecologists have recently emphasized the need for reappraisal of objectives in applied entomology. There are ever-increasing examples where the chemical solution to one pest problem has only given rise to or increased the problems with other pests. In 1943 Pickett and his co-workers (see especially Pickett and Patterson, 1953) initiated a study of the influences of spray practices on the fauna of apple orchards in Nova Scotia. They presented striking evidence of disturbances of natural control of certain pest insects and mites. Hazeman (1950), Ullyett (1951), DeBach (1951), Wille (1951), Painter (1951), Rodriguez and Rodriguez (1952), Fleschner (1952), Griffiths 1953), Solomon (1953), Huffaker and Kennett (1953), Michelbacher (1954), and Clausen (1954), also described some of the hazards of overemphasis of chemical control and stated the desirability of research along lines of host-plant resistance, cultural and nutritional 
manipulations, and the use of insecticides in ways least disturbing, or most conducive, to existing natural controls.

Solomon (1953) argued for studying the total environments, and pertinently stated, "But on the whole, little progress has been made toward redressing the balance between chemistry and biology in this biological field." However, the recently instituted "supervised control" of insect pests in several western states is a notable landmark (Smith and Allen, 1954).

Critical reading of such studies or reviews on animal populations as those by Allee et al. (1949), Odum (1953), Nicholson (1933, 1954), Smith (1935), Solomon (1949), Elton (1942), and Errington (1946) would reveal that compensating mechanisms tending to stabilize are intrinsic characteristics of all levels of life; that regulatory mechanisms cause intense mortality in dense populations but relax in intensity ${ }^{5}$ as populations decline to low levels, and may operate to alter rates of reproduction as well. Factors which do not act in such a manner are not regulatory, although they may set the stage or furnish the requisites for regulatory action. Important chance fluctuations, particularly in unstable environments, may, however, be largely attributed to the action of such factors as climate, in drastically and suddenly decimating the supply of livable abodes for example. This operation is within potentials of very wide amplitude. But, depletion of other requisites always sets an upper limit to such fluctuations. Economic entomology that ignores this interplay of natural forces is shortsighted.

\section{Population Changes and the Holocoenotic Environment}

Populations are viewed as being regulated by the density-dependent features of their own ecosystems, even though distinct populations of relatively independent systems may be influenced synchronously by some extrinsic force acting as a common denominator in the equations of the several ecosystems. Density-independent factors are becoming recognized as basic to the truly regulatory action-a recognition that the factors of the environment act interdependently (holocoenotic principle). This interdependence stems from the fact that certain density-independent factors furnish or condition the existence of the requisites for which competition (density-dependent action) occurs. If such factors determine the framework of favorable gross habitats, the quantities and kinds of foods available, the number and quality of protective cover features or security of position, and the existence of allies and enemies, and if they may even alter the degree and specific kind of densitydependent action in time and place, then it cannot be maintained that density-dependent control is independent of such factors. Specific actions are "patchy" but intergrading in time and place. Density-dependent actions cannot occur in a vacuum. Density-independent features fix their potentials. Nicholson (1954) has termed such density-independent factors "rule-making" or "legislative," in contrast to the "rule-enforcing" or truly governing factors. It should be understood that the two aspects occupy positions of full parity-such are the complete interdependencies. They are not really contrary explanations. Their roles are fundamentally different. If depletion of

\footnotetext{
5 "Undercrowding" may operate in an opposite, hazardous fashion at very low densities.
} 
requisites did not limit numbers, populations would be as infinite on a single oak tree as on million, and the fact that the number of trees is determined by density-independent factors would be meaningless. It would be just as meaningless to try to visualize density-dependent action over the population of an oak-infesting insect if climate permitted no oaks!

The synchrony in cyclic phenomena of populations as discussed by various authors (for example, Errington, 1954) may be the result of an unknown common denominator, not implied as extramundane. Lack (1954), Hutchinson (1954), Rowan (1954), and others have recently emphasized that apparently broad cyclic synchronies in reality fall under a pattern of causes that are biological in nature and intrinsic to the respective systems, whether or not they are an expression of "random fluctuation with serial correlation" (Cole, 1954). Cole and others have emphasized that an effect of his thesis is the channelling of effort more toward finding the biological causes within the ecosystems, and less toward looking for "mysterious" explanations.

Errington (1946) wrote,

Greater departures in predation patterns from the simpler ones shown by invertebrates and lower vertebrates may naturally be expected in higher vertebrates better able to take care of themselves individually and manifesting more territoriality in one way or another.

He considered such simpler populations as "greatly more subject to limitation through food or predation than are the strongly territorial" forms. Territoriality is seen as an evolutionary product of self-limitation against overpopulation and against the more unstable, more violent effects of such biotic interactions, which are characteristic in the absence of such devices. This is in line with the view that food, although limiting the maximal levels attainable by populations, is not the dominant feature regulating the densities of populations of the vast majority of species. Food utilizers at the peak of the hierarchy, such as the ungulates or other higher vertebrates, even man, exist at characteristic equilibria as a result of various mechanisms tending to effect a shift in the factors that control their densities-malnutrition, for example - to such limiting requisites as shelter or space requirements, regardless of whether the latter are absolute or only relative and psychological. It would be interesting to learn the role of releaser mechanisms (Tinbergen, 1953) in establishing patterns of territorial behavior and the relation of the evolutionary origins of such behavior as adaptations insuring against intense predation, disease, or starvation.

For the ungulates, Errington (1946) has concluded that both predation and food supply are operative-that predation is only meaningful at levels approaching the point where food becomes limiting. If the level of a given food plant is the primary limiting mechanism for the population of a given ungulate consumer, then the food plant must not be the factor which is limiting for the abundance of utilizers of a lesser category, of which there are many more species; otherwise these must be either utilizers of an incidental or nondestroying nature, or else their numbers must be regulated by still other checks, such as predation, at levels below that permitted by that food supply. Does it not conform to evolutionary pattern that the ungulates should be checked not at levels far below their food supply, but at levels 
consistent with near maximum utilization yet below the point of tearing down the complexity and richness of the ecosystem, including the parent soil itself ? It is considered that the checks on ungulates, for example, operate at the point where malnutrition (contributing to weaklings, strays, and disease) has set in but is not intensely felt, with predation acting in partnership.

In the crazy-quilt pattern of causes and effects, the tangled web of ecosystems may have some order under the dominant action of competition, with restricted food commonly the dominant factor for a minimum of species; with certain kinds of disease next in order, again affecting a minor number of species, but occupying a rear-guard claiming position close to and affiliated with food supply; with predation, including entomophagous parasitism, accounting for regulation of the densities of still greater numbers of species; and, perhaps, the limitation of favorable habitats or abodes, with interactions, occupying the position of influence over a greater number of species than any other of the density-dependent category. Many of these factors may operate in conjunction with others, or in ways which activate others. For example, competition for protective abodes may have significance as security against predation, or simply as protection against annihilative temperatures or desiccation. The food itself may be the protective cover.

\section{Simpler Relations of Simple Communities}

Owing to the integration of complex natural communities, the changes occurring in response to changes in any single factor are usually less severe than with simpler natural communities or "artificial" communities (Allee, et al., 1949, pp. 695, 674). Hence it is within theory that insect pests are usually more severe on crops or pure-stand timber than on acceptable host plants within complex stands of native vegetation, and that in unnatural situations single factors that dominate changes in density can often be demonstrated, although the key factor may vary in time and place.

That single critical biotic factors operating within a favorable ecosystem are sometimes responsible for the densities of certain populations of both plants and animals has been demonstrated many times by biological-control ecologists. Examples are the control of prickly pear by the moth Cactoblastis cactorum Berg, in Australia (Dodd, 1940); of Klamath weed (St.-John'swort), Hypericum perforatum L., by the leafbeetle Chrysomela gemellata Rossi, in California (Holloway and Huffaker, 1951) ; and, among the many insect examples, the classical control of the cottony-cushion scale, Icerya purchasi Maskell, by the Vedalia beetle, Rodolia cardinalis Mulsant, in California citrus.

On the other hand, because of greater potentials for compensation, the relations in complex communities are such that it is not so easy to demonstrate the dominance of single factors. Hence, because of the greater complexity of floral and faunal relations in forests, as compared with that of crop production, the mounting use of chemicals in control of forest pests is all the more unpredictable and embodies a possible sequence of very serious economic consequences (Park, 1948). 


\section{The Role of Predation}

Much of the published writing on predation is based on work with vertebrates and tends to minimize the role of predators in the control of prey populations. Thus Errington (1937) concluded, with respect to the higher vertebrate predators,

Predators may occasionally starve, and predator pressure may at times be about all that a prey species can stand, or conceivably more than it can stand; but, for all that, predation still seems to be essentially a by-product of population rather than a broadly dominant influence on population.

However well that statement may apply to vertebrate predation, it cannot apply to predation in general. Such vertebrate predators are euriphagous (general predators) and neither quickly responsive, reproductively, to increases in prey, nor adequately supplied by any one prey species at all seasons. As to food, they are dependent upon the level at the most critical period and are not equipped to exert dominant controlling action over the densities of a given species. Lack (1954) provides an interesting theoretical explanation of the complexity of action by such predators: he assigns a meaningful role to predation on the populations of alternate prey species (birds), made possible by build-up in numbers of predators resulting from increases in their basic rodent diet, in spite of the fact that their predation on the rodents was not considered controlling. Errington (1946), in his masterful review, significantly modified his earlier view, admitting greater likelihood of meaningful predation among invertebrates. He also stated (p. 145), "Experimental manipulation of vertebrate populations has been tremendously handicapped by technical and economic obstacles, and many readers will probably be disappointed in how little the literature shows in this respect."

In fact, other than Gause's (1934) famous experimental work on predation of Didinium nasutum Müller on Paramecium caudatum and the work of Foerster and Ricker (1941) on fish predation, most of the limited experimental work on predation has involved insects and mites. Even in some of the latter work, the evidence has been rather fragmentary, lacking in adequate control data, or almost wholly undocumented. Some useful examples of the experimental evaluation of predation among the insects and mites are those of Doutt (1951), Doutt and Hagen (1950), Smith and DeBach (1942), DeBach, Fleschner, and Dietrich (1951), Lord (1949), and Clancy and Pollard (1952). We hope that the present five-year experimental study of predation under field conditions will prove a useful addition to existing examples, especially since an acaricide was used to remove predators from control plots and thus permit direct comparison of field populations under predator-present and predator-absent conditions. The most important ecological aspects of this study are presented under the next heading.

Errington (1946) inclined to negate predation forces on populations having self-regulatory aspects, and to place much emphasis upon "thresholds of security" or security habitats. This is debatable. These concepts have many relative aspects, and the lines are hard to fix. All populations, even if under 
dominant control by a specific predator, have certain low levels of density representing security from predation, which are associated, in one way or another, with highly protective refuges, self-limitations involving territoriality, or just plain unlikelihood of encounter as the numbers become fewer and fewer and as space-coverage requirements increase for the predator.

Errington also considered predation by vertebrates to be largely nonregulatory, except for cases of predation by the Canidae. He called attention, too, to the possibility of greater use of "marginal" habitats by prey species, except for predation. His obvious hesitancy to generalize is understandable. Each population of animals is influenced to different degrees by many factors, both in time and place. Predation is only one regulatory mechanism, sometimes significant, sometimes not. Errington considered the Canidae as exhibiting the cunning and selectivity ("not unlike the hunting activities of man") of a highly specialized, selective predation.

The Canidae, among the vertebrates, are simply more ecologically similar to effective predators among the invertebrates than are the less effective predatory vertebrates. The arthropod predators that are capable of most effective economic control of arthropod pests of crops are those which are highly selective as to prey, have requirements as to general habitat and behavioral reactions that are closely linked (adapted) and synchronized in every way with the characteristics of the prey, and which are, therefore, readily reactive and reproductively responsive, without prolonged delay, to increases in density of the prey above rather low-density threshold levels.

Allee et al. (1949, p. 373) stated that stenophagous or monophagous predators, such as ant- and termite-eaters, are the exception rather than the rule. It cannot yet be said that this is so relative to invertebrate predation, if, indeed, it is representative of vertebrate predation. Thompson (1951) discussed prey specificity of predatory insects and concluded,

In reality although predators may be a good deal less specific in their food habits than [entomophagous] parasites the difference is not I suspect as great as we have been led to believe.... In reality their behavior, just like their morphological characteristics, is specific and adaptive but the adaptive action is based, so to speak, on a foundation of specificity.

He also pointed to the much greater degree of host specificity of phytophagous insects than has been generally considered. (See also Dethier, 1947, and Thorsteinson, 1953.) Fleschner and Ricker (1954) and the present example also point to a marked prey specificity of certain predatory mites.

If we broaden the common entomological concept of an entomophagous parasite and consider it, as did Nicholson (1954) and as do many parasitologists, as a special type of predator rather than a parasite, then relative prey specificity among the insects would assume a much more general pattern. By their nature as ecological parameters in population dynamies, entomophagous parasites are more nearly related to predators than to parasites in the usual sense. Each host-searching adult renders the destruction of each individual host (or prey) contacted (and many more than one is the rule) even though the actual destruction is a delayed reaction to that contact, and is accomplished by the offspring resulting from the adult's contacting prey. 


\section{Prey/Plant and Predator/Prey Interactions as Alternative, Regulating Mechanisms (Present Data)}

More knowledge of insect and mite predator/prey interactions may help to resolve basic questions in population dynamics. The Typhlodromus/Tarsonemus interaction occurs at levels of prey density much below the point where other factors appreciably influence prey densities during the reproductive season. General predators, or any predators feeding on less preferred prey and not closely dependent upon that prey, have no mutually dependent interaction with that prey, and obviously may exhibit only partial, erratic, or entirely compensatory effects upon populations of that prey. However, all accumulated evidence makes it clear that the depressive effects of factors other than predation, to the degree that they would operate in the presence of predator/prey balance under the conditions of the present experiments, would not have density-regulating action. Any resulting population-depressive tendency is purely compensatory and merely a substitute for deaths by predation. Predation in this case obviously has a primary, swamping or superimposed pressure in relation to other causes of mortality.

Regarding experimental studies of oscillations, Gause (1934) presented evidence to the effect that predator/prey interaction is self-exterminating. He was able to maintain populations of Didinium nasutum preying on Paramecium caudatum only by repeated introductions of both predator and prey species. Winsor (1934) and Nicholson (1954) criticized his work, the latter author stating "... the oversight by Gause of the essential space component of the Volterra equations caused him to design inappropriate experiments to test the validity of these equations, and therefore to reach an erroneous conclusion."

While the present evidence is not conclusive in this respect, and was obtained without limitation of the fauna to predator and prey species and from a very complex universe, as compared to a simple, completely controlled one, there seems reason to feel that predator/prey oscillation, at least in some natural biological systems, is not self-exterminating. Sustained equilibrium at very low densities seems to be a primary characteristic of the cyclamenmite/predator interaction. The evidence gathered during five years of study indicates that extermination on any small group of plants, or perhaps even on a single plant, of either predator or prey species is unnatural. Increments of either predator or prey from without are not essential. As previously discussed, the graduated difficulty which predators have in locating the last of the prey species in maximal security positions prevent extermination. The authors have no experimental evidence on this point, but feel that the complexity or diversity of habitats or refuges is a greater assurance of perpetuating oscillations than is simple increase in uniform space.

The data presented in the present study, particularly figures $1 A$ and $1 C$, exemplify a principle which may be of rather broad occurrence as factors in nature shift in time and place. Under one set of conditions density-dependent action often is in the form of competition for a given requisite, such as security from enemies, and a balance exists that is characteristic for the general, although continually modified, conditions ; other more varied conditions, on 
the other hand, may entail a different characteristic regulatory action and population balance. There is always an interwoven chain of densitydependent actions, sometimes suddenly and sometimes more gently altered by the density-independent parameters which fix their potentials.

MacLeod (1938) and Burnett (1948) have discussed the importance of temperature as a factor determining whether control of the greenhouse whitefly, Trialeurodes vaporariorum Westwood, by Encarsia formosa Gahan, is effective. DeBach et al. (1955) presented similar results relative to biological control of California red seale, Aonidiella aurantii (Mask.) in citrus groves of California by Aphytis lingnanensis Compere. A density-independent factor such as temperature, however, largely serves to release a population from regulatory action of a given density-dependent factor ; it remains for regulatory action to be established again at some higher level of density by action of some other density-dependent mechanism-competition for food being the axiomatic last bulwark.

In the present case, figures $1 A$ and $1 C$ demonstrate the effect of such a shift in the regulatory action. Temperature, humidity, or light condition may have contributed to minor changes seen in figure $1 C$ over short periods of time, but the fact that there were large general oscillations of population, with the densities showing a consistent pattern of ascent or decline over periods of five or six successive weeks, and the fact that the total picture of oscillations aligned in a regularized manner, occurring at intervals of roughly two and one-half to three months, regardless of seasonal changes, indicate that temperature and general humidity variables were not important. The shift in the regulating mechanism in this case accounts for the different oscillatory patterns of figures $1 A$ and $1 C$, both quantitative and qualitative-an effect of the arbitrary restriction of predation in $1 C$ and its existence in $1 A$.

In the presence of the predator (fig. $1 A$ ) the prey changes in density in a regularized manner; the amplitude of successive oscillations are very small, the peaks of density occur at levels noninjurious to the strawberry plants, and the period of the oscillation is more prolonged (four to six months in duration) than in figure $1 C$. The period of the cycle is prolonged at least in part by the ability of this predator to sustain itself for long periods at very low densities of its specific prey. Its habit of utilizing honeydew and other liquid nourishment, previously mentioned, is considered a factor of importance. This prevents the near extinction of the predator population at very low prey densities, and makes possible the rapid recovery and reproductive response to increases in prey. Physical barriers of many thousands of tiny hairs, spines, and leaf crevices, some more restrictive at certain phases of growth to predators than to prey, usually enable at least some of the prey to survive. A combination of maximum security for the few and the reduced success of predation at low prey densities results in a low-density minimum below which predation does not reduce the prey population.

There is also a rough high-density maximum above which predation increased so intensely that gradual decline of prey ensued. Since the amplitude was small, there being slight difference in the densities (relative to possible differences) between the troughs and the peaks of an oscillation, the decline in prey densities with rise in predator densities was gradual, as was the afore- 
mentioned decline in predator densities. The increase in prey densities, as well as the increase in predator densities, such as occurred in early and late August and again in early and late December, was rapid as compared with the decline. Moreover, the general decline in predators in each wave somewhat belatedly accompanied the decline of cyclamen mites, and the most pronounced, consistent increases in predators (indicating greater adequacy of sampling) similarly followed only slightly the most pronounced spurts in prey densities. Twice during the tests, on October 6 and again on January 20 , the predator densities recorded were too low for general trend lines, represented by dotted-line segments at those positions. Sampling perhaps gave a poor reflection of reality on those dates. The explanation is not known. However, there is a regularized nature of fluctuations, with predator and prey densities reciprocally dependent.

In figure $1 C$, there is seen the operation of intraspecific competition for both food and abode, with the two in interaction, since the food is also abode or cover.

The cyclamen-mite densities are seen as a series of oscillatory waves or regularized fluctuations of decreasing amplitude. Considered independently of figure $1 A$, this is not a case of oscillation due to predator/prey interaction but is in the absence of predators. It is, nevertheless, an oscillation resulting from biotic interaction, the physical factors of the environment acting primarily in an indirect manner and as a result of that interaction. The biotic interaction in this case is one resulting from the cyclamen mite's feeding on the strawberry plants and the resultant alteration of the host plants as both abode and nutriment for the mite. Strawberry plants undergo a natural deterioration with age, and this deterioration itself is a marked contributor to reduced potential for high cyclamen-mite densities. However, the youth of these plants even at the end of the tests (beginning their third year) was such that the markedly reduced amplitude of each successive wave is explained primarily on the basis of cyclamen mite/host plant interaction, rather than simple aging of the plants.

In the absence of effective predation, the cyclamen mite, or prey, under favorable host-plant conditions and under a rather wide range of temperature, develops very high densities on strawberries. Increase in geometric manner is exhibited in many of the sudden spurts in population of this mite, as seen in the surge of figure $1 C$ just after April 8 and in figures 2, 3, 4, and 5 . The injury to the host plants, as described in a previous section, greatly lowers the plants' capacity to sustain high prey populations, both nutritionally and as to microenvironmental requirements. Hence, a crash results after a variable period of sustained high densities. Only after densities have subsided to rather low levels, as seen on July 25, December 7, and March 2, do the plants recover sufficiently so that conditions favorable to prey increase are reëstablished. The occurrence of three such population ascents, leveling off at temporary and rough "asymptotes," and subsequent declines to trough positions, is seen. A fourth ascent was made in April at the end of the experiment. The decreasing level of the "asymptote," or peak, positions is related to the degree of weakening and deterioration of the host plants as a result of the previous waves of infestation. Hence, competition for food and abode 
limitations explains this pattern of regularized fluctuation, and this pattern was made possible only by the arbitrary restriction of predation. There is competition for limited requisites. The requisites, as such, are reactive to the intensity of that competition, and not simply restricted to specific levels by the physical parameters.

Independent of figure $1 C$, there is obvious correlation between the predator and prey populations shown in figure $1 A$. Such correlation is often cited as evidence of controlling action of predators or entomophagous parasites. Correlation would be normal to such predation, even if that predation were nothing more than a "by-product of population rather than a broadly dominant" determinant of population, to use Errington's (1946) words. In this case, however, the direct paired-plot experimental evidence, contrasting prey populations under predator-present and predator-absent conditions, is conclusive.

\section{The Role of Reproductive Rate}

Relative to the importance of rate of reproduction, Smith (1935) called attention to the emphasis by Darwin that "... there is no correlation between reproductive capacity and average population density." He also stated, "One effect of high birth rate is that it enables a species quickly to take advantage of an increase in the capacity of the environment for it, but it does not determine that capacity." However, it may be one important influence on interim population levels. In some populations that are characteristic of rigorous environments, the interim conditions may predominate in the history of a species. In addition, generally exterminative off-season features may cause reproductive rate to assume great importance at the resumption of each reproduction season, with the forepart of each annual cycle representing an interim period of partial relaxation from limits imposed by other factors. However, the limited survival during the off-season itself has a densitydependent feature.

Hutchinson (1954) has suggested that in most eases natural selection operates to reduce the time lag and violence or amplitude of oscillations (these are dangerous and extinction at low density positions is more likely) "... which may best be done no doubt by making natality less density dependent so that the burden of regulation is placed on mortality." Significantly, it is neither natality nor mortality that is regulatory, but the causes of natality and mortality. Allee et al. (1949, p. 391) emphasized that they do not explain population size: "The responses [natality and mortality], as end products, are intimately under the genetic and ecological factors that emerge from the reciprocal interaction between the population and its environment." Thompson (1939) has emphasized this point.

No implication is intended that Hutchinson does not fully appreciate this distinction. The point is made because of the views expressed in a prominent text by Andrewartha and Birch (1954), whereby an entire "theory" of the abundance of animals is based upon a descriptive statistic $r$, expressing net population change, either positive or negative. The important feature is not the value of $r$ but the causes behind the value. There is evidence that this is 
misleading with regard to understanding the concepts of density-dependent actions in population dynamics.

Population growth or decline trends are the product of causes which affect net decreases or net increase by acting through either natality or mortality, or both. However, as Hutchinson stated, the great emphasis is on causes of mortality when populations approach their maxima ; it is on causes of natality when competitive pressures are relaxed.

This is contrary to the view (Birch, 1953) that reproductive capacity is of prime importance. Errington (1954) argued for less emphasis on numerical fluctuations of cyclic phenomena and more attention to factors causing changes in reproductive behavior or capacity. Yet he recognized that habitat capacity rather than reproductive capacity is of prime importance. His emphasis has much merit as a method of uncovering causes which are regulatory. Reproductive changes are only in reaction to other more fundamental density-dependent causes. This is so whether or not a given density under one set of conditions produces a series of reactions of an entirely different complex from that which it produces (or an even lower density may produce) under different conditions. It is also true irrespective of any interwoven psychophysiological effects.

Birch (1953) implied a cause and effect relation between intrinsic rate of increase and maximum numbers of Calandra oryzae L., although he stated, "The upper limit to numbers was not due to food shortage or insufficient space to hold more insects, but to the particular way in which crowding affects the rate of increase." There is no basis for his having plotted numbers of adults against rate of increase, for there can be no linear relation between the points he used. Also, the very variables used to achieve the different rates of increase are the same variables which affected critical requisites and $i n$ directly population numbers. He varied food, moisture content of grain, and temperature, and used two strains of $C$. oryzae and also Rhizopertha dominica Fab. as test insects. It is not possible to infer, therefore, that the different rates of increase are a cause of observed differences in maximum numbers or weights of adults. As Nicholson (1954) emphasized, if a physical factor or any other important factor is changed, equilibria positions may be altered. The higher temperature used may be assumed to increase the intensity of competition for space (crowding).

Even when actual space remains the same, if there is a decrease in tolerance to crowding, physiologically or behavioristically, for example, then space (a relative concept) is a very real requisite in short supply and is the cause of the different maxima, if indeed crowding, as Birch implied, is the key feature. It is interesting that Rhizopertha dominica had the same maximum number regardless of very different rates of increase under the two temperatures. This shows that neither the difference in temperature nor the associated difference in rate of increase changed the upper limit. Some factor uninfluenced by either, limited numbers. Birch's data suggest that relative crowding in these two species under the conditions used limited the numbers by changing natality/mortality ratios, and that natality was relatively more influenced in Calandra oryzae and mortality in R. dominica. 


\section{SUMMARY}

Realization of the interrelation in the action of factors of the environment in population dynamies is beginning to assume importance in the minds of economic entomologists. As a result, there is an increasing group of workers in this field who believe that fundamental studies along ecological lines must form the basis of further advances, and that biological control and other concepts of ecological control have been badly neglected. Chemical control incompatible with existing natural forces must be realigned. Practical compromise solutions are proving possible.

This study experimentally demonstrates the vital role of predation by a predatory mite, Typhlodromus cucumeris or T. reticulatus or both, in the control of the cyclamen mite, Tarsonemus pallidus, on strawberries. Analyses of population trends of the cyclamen mite and its chief predator were made over a period of five years. By stocking one plot of a pair with predators, and leaving the other unstocked, and by preventing natural invasion of predators in the check plot, it has been possible to demonstrate very marked economic control of the prey species by this predator. During the last two years, a total of eleven such paired series of data was obtained. The total number of cyclamen mites sampled on thirty leaflets from each plot on four different dates in 1953 and 1954 was 69,630 in the predator-free plots, as compared with 3,075 in the predator-stocked plots. The population trends indicated direct reciprocally dependent oscillations in numbers of the predator and its prey.

Natural predator invasion of infested fields normally gives sporadic control in second-year berries and good control in third- and fourth-year berries - a result of delay in entrance of the predators. Stocking of fields with predators has given complete economic control, but this has as yet been done only on a trial basis. Deliberate introduction into the fields of the pest mite along with the predator early in each planting is the obvious next step, in order to achieve the earliest possible establishment of equilibrium at low prey densities, thereby effecting economic control.

Broad statements minimizing the role of predators in regulating the numbers of their prey are invalid. In this example, predators controlled the fortunes of the prey; other causes of mortality appeared to be only a substitute for death by predation. Elements of the physical environment are viewed as nonregulatory in nature, but with full parity. They may act in the following ways: (1) they may furnish or condition the given levels of the requisites, thus setting the potentials within which all competition (regulatory, or density-dependent action) occurs; (2) they may exert action which shifts the specific density-dependent controlling action in kind, in time, and in place; and (3) they may also have important chance influence of density-independent nature on various types of relaxed or interim population levels which, for one reason or another, may exist in time or place at positions free from the common, strong competitive pressures. The latter factor in reality is an aspect of the degree of favorableness for multiplication during the time lag between the period of action of one severe competitive mechanism and that of another. Collectively, these mechanisms intergrade with one another, are 
semicontinuous, but of erratic intensity of action, and somewhat "patchy" in distribution in time and place.

The laws of population dynamics are the same everywhere, and are the same as those which determine the distributions of animals, as stated by Andrewartha and Birch (1954); but the proper interpretation or integrating concept of those laws is not as those authors outlined. Competition for requisites, food and a place in which to live secure from harm, constitutes all really regulatory, or density-dependent, action. Allies and natural enemies alike are parameters of this simple equation, influencing success or failure in achieving maximum utilization of food and attainment of security.

\section{LITERATURE CITED}

Allee, W. C., A. E. Emgrson, O. Park, T. Park, and K. P. SchmidT

1949. Principles of animal ecology. 837 pp. W. B. Saunders Co., Philadelphia, Penn.

ANDREWARTHA, H. G., and L. C. BIRCH

1954. The distribution and abundance of animals. $782 \mathrm{pp}$. University of Chicago Press, Chicago, Ill.

BIRCH, L. C.

1953. Experimental background to the study of the distribution and abundance of insects. II. The relation between innate capacity for increase in numbers and the abundance of three grain beetles in experimental populations. Ecology 34:712-26.

BUNYEA, H.

1942. Fowl pox (diphtheria). Yearbook Agr. 1942:977-86.

BURNETT, T.

1948. Modal temperatures for the greenhouse whitefly Trialeurodes vaporariorum and its parasite Encarsia formosa. Ecology 29 :181-89.

Clancy, D. W., and H. N. Pollakd

1952. The effect of DDT on mite and predator populations in apple orchards. Jour. Econ. Ent. 45:108-14.

Clausen, C. $\mathbf{P}$.

1954. Biological antagonists in the future of insect control. Agr. Food Chem. 2:12-18.

CoLE, L. C.

1954. Some features of random population cycles. Jour. Wildlife Mangt. 18:2-24.

DEBACH, $\mathbf{P}$.

1951. The necessity for an ecological approach to pest control on citrus in California. Jour. Econ. Ent. 44:443-47.

DeBach, P., C. A. Fleschner, and E. J. Dietrich

1951. A biological check method for evaluating the effectiveness of entomophagous insects. Jour. Econ. Ent. 44:763-66.

DeBACH, P., T. W. Fisher, and J. LANDI

1955. Some effects of meteorological factors on all stages of Aphytis lingnanensis, a parasite of the California red seale. Ecology 36:743-53.

DETHIER, V. G.

1947. Chemical insect attractants and repellents. 289 pp. Blakiston Co., Philadelphia, Penn.

DoDd, A. P.

1940. The biological campaign against prickly-pear. 177 pp. Commonwealth Prickly

DouTr, R. L. Pear Board, Brisbane, Queensland, Australia.

1951. Biological control of mealybugs infesting commercial greenhouse gardenias. Jour. Econ. Ent. 44:37-40.

DOUTT, R. L., and K. S. HAGEN

1950. Biological control measures applied against Pseudococcus maritimus on pears. Jour. Econ. Ent. 43:94-96. 
Euton, C.

1942. Voles, mice and lemmings; problems in population dynamics. $496 \mathrm{pp}$. Clarendon Press, Oxford, England.

ERrington, P. L.

1937. What is the meaning of predation Smithsn. Inst. Ann. Rept. 1936:243-52.

1946. Predation and vertebrate populations. Quart. Rev. Biol. 21:144-77.

1954. On the hazards of overemphasizing numerical fluctuations in studies of "cyelie" phenomena in muskrat populations. Jour. Wildlife Mangt. 18:66-90.

FlesChNer, C. A.

1952. Host-plant resistance as a factor influencing population density of citrus red mites on orchard trees. Jour. Econ. Ent. 45:687-95.

Fleschner, C.-A., and D. W. RICKer

1954. Typhlodromid mites on citrus and avocado trees in southern California. Jour. Econ. Ent. 47:356-57.

FOERSTER, R. E., and W. E. RICKER

1941. The effect of reduction of predaceous fish on survival of young sockeye salmon in Cultus Lake. Fish. Res. Bd. Canada Jour. 5:315-36.

GaUSE, G. F.

1934. The struggle for existence. $163 \mathrm{pp}$. Williams \& Wilkins, Baltimore, Md.

GRIFTITHS, J. T.

1953. Where do we go from here Florida Ent. 36:135-40.

HAZEMAN, L.

1950. Controlling insect pests through their nutritional requirements. Jour. Econ. Ent. 43:399-401.

HoLloway, J. K., and C. B. HUFFAKER

1951. The role of Chrysolina gemellata in the biological control of Klamath weed. Jour. Econ. Ent. 44:244-47.

HUFFAKkR, C. B., and C. E. KENNETT

1953. Developments toward biological control of cyclamen mite on strawberries in California. Jour. Eeon. Ent. 46:802-12.

HUFFAKFR, C. B., and C. H. SPITZER, JR.

1951. Data on the natural control of the cyclamen mite on strawberries. Jour. Econ. Ent. 44:519-22.

HutCHinson, G. E.

1954. Theoretical notes on oscillatory populations. Jour. Wildlife Mangt. 18:107-9.

LACK, D.

1954. Cyclic mortality. Jour. Wildlife Mangt. 18:25-37.

LORD, F. T.

1949. The influence of spray programs on the fauna of apple orchards in Nova Scotia.

III. Mites and their predators. Canad. Ent. 81:202-14, 217-30.

MCLEOD, J. H.

1938. The control of the greenhouse whitefly in Canada by the parasite Encarsia for. mosa Gahan. Sci. Agr. 18:529-35.

Michelbacher, A. E.

1954. Natural control of insect pests. Jour. Econ. Ent. 47:192-94.

Nicholson, A. J.

1933. The balance of animal populations. Jour. Anim. Ecol. 11:132-78.

1954. An outline of the dynamies of animal populations. Austral. Zool. 2:9-65.

ODUM, E. P.

1953. Fundamentals of ecology. 384 pp. W. B. Saunders Co., Philadelphia, Penn.

PAINTER, R. H.

1951. Insect resistance in crop plants. 520 pp. Macmillan Co., New York, N.Y.

PARK, T.

1948. Population ecology. Encyclopaedia Britannica. 5 pp.

Pigkeit, A. D., and N. A. PATTEerson

1953. The influence of spray programs on the fauna of apple orchards in Nova Scotia. IV. A review. Canad. Ent. 85:472-78. 
RODRIGUEZ, J. C., and L. D. RODRIGUEZ

1952. The relation between minerals, B-complex vitamins and mite populations in toROWAN, W. mato foliage. Ent. Soc. Amer. Ann. 45:331-38.

1954. Reflections on the biology of animal cycles. Jour. Wildlife Mangt. 18:52-60.

SMITH, H. S.

1935. The role of biotic factors in the determination of population densities. Jour. Econ. Ent. 28:873-98.

SMITH, H. S., and P. DeBACH

1942. The measurement of the effect of entomophagous insects on population densities of their hosts. Jour. Econ. Ent. 35:845-49.

1953. Artificial infestation of plants with pest insects as an aid in biological control. Seventh Pac. Sci. Congr. Proc. 4:225-59.

SMITH, L. M., and E. V. Golds MitH

1936. The cyclamen mite, Tarsonemus pallidus, and its control on field strawberries. Hilgardia 10:53-94.

SMith, R. F., and W. W. AlleN

1954. Insect control and the balance of nature. Sci. Amer. $190: 308-42$.

Solomon, M. E.

1949. The natural control of animal populations. Jour. Anim. Ecol. 18:1-35.

1953. Insect population balance and chemical control of pests. Pest outbreaks induced by spraying. Chem. Indus. 1953:1143-47.

Thomas, H. E., and C. P. Marcus, JR.

1953. Virus diseases of the strawberry. Yearbook Agr. 1953:765-69.

THOMPSON, W. R.

1939. Biological control and the theories of interactions of populations. Parasitology $31: 299-388$.

1951. The specificity of host relations in predaceous insects. Canad. Ent. 83:262-80.

Thorsteinson, A. J.

1953. The role of host selection in the ecology of phytophagous insects. Canad. Ent. 85; 276-82.

TINBERGEN, $\mathrm{N}$.

1953. Social behavior in animals. $150 \mathrm{pp}$. John Wiley \& Sons, New York, N.Y.

ULLYETT, G. C.

1951. Insects, man and environment. Jour. Econ. Ent. 44:459-64.

WILCox, J., and A. F. HowLAND

1955. Control of the strawberry aphid in southern California. Jour. Econ. Ent. 48:58183.

WILLE, J. E.

1951. Biological control of certain cotton insects and the application of new organic insecticides in Peru. Jour. Econ. Ent. 44:13-18.

Winsor, C. P.

1934. Mathematical analysis of growth of mixed populations. Cold Spring Harbor Sym. posia on Quant. Biol. 2:181-87. 
The journal Hilgardia is published at irregular intervals, in volumes of about 600 pages. The number of issues per volume varies.

Subscriptions are not sold. The periodical is sent as published only to libraries, or to institutions in foreign countries having publications to offer in exchange.

You may obtain a single copy of any issue free, as long as the supply lasts; please request by volume and issue number from:

Agricultural Publications

Room 22, Giannini Hall

University of California

Berkeley 4, California

The limit to nonresidents of California is 10 separate issues on a single order. A list of the issues still available will be sent on request.

In our publications it is sometimes convenient to use trade names of products or equipment rather than scientific identifications. In so doing it is unavoidable in some cases that similar products which are on the market under other trade names may not be cited. No endorsement of named products is intended nor is criticism implied of similar products which are not mentioned. 